\title{
Practical Approaches to Treating Obesity: Patient and Healthcare Professional Perspectives
}

\author{
Donal O’Shea $\cdot$ Scott Kahan $\cdot$ Lorna Lennon $\cdot$ Cathy Breen
}

Received: March 10, 2021 / Accepted: April 15, 2021 / Published online: April 30, 2021

(C) The Author(s) 2021, corrected publication 2021

\begin{abstract}
Obesity is a chronic and treatable disease carrying risk for numerous health complications, including cardiovascular disease, respiratory disease, type 2 diabetes mellitus and certain cancers. While there is a great need to address the topic in clinical practice, healthcare professionals (HCPs) often struggle to initiate conversations about weight. In this paper, guidance on how to raise and address the subject of weight with individuals is provided from an HCP and patient perspective using the 5As framework. This model facilitates advising individuals on the benefits of weight loss and supports them to develop achievable and sustainable weight management plans. With obesity rates still rising across the globe, it is imperative that more HCPs become skilled in raising and addressing the issue.
\end{abstract}

Keywords: Counselling; Obesity; Patient view

\footnotetext{
D. O'Shea

University College Dublin, Dublin, Ireland

S. Kahan

George Washington University, Washington, D.C, USA

C. Breen $(\square)$

St Columcille's Hospital, Dublin, Ireland

e-mail: cathy.breen@hse.ie
}

\section{Key Summary Points}

Why carry out this study?

Obesity is chronic and treatable, and confers risk for numerous health conditions including cardiovascular disease, type 2 diabetes and, more recently, severe COVID-19; however, despite this, global incidence is rising.

As such, there is a pressing need to address it in clinical practice; however, healthcare professionals often struggle to initiate conversations about weight.

This paper provides guidance on how to sensitively and effectively address the topic of weight from the perspective of both a healthcare professional and people living with obesity through use of the $5 \mathrm{As}$ framework.

\section{What was learned from the study?}

The 5As framework for tackling obesity in clinical settings was described in detail, with relevant examples. 
While primary care physicians are central to managing obesity, a multidisciplinary approach involving all care providers should be utilised to consider environmental and psychosocial influences impacting obesity, and to address psychological and physiological challenges associated with achieving and sustaining long-term weight loss.

The 5As framework is transferable across disciplines.

\section{DIGITAL FEATURES}

This article is published with digital features, including a summary slide, to facilitate understanding of the article. To view digital features for this article go to https://doi.org/10.6084/ m9.figshare. 14407043

\section{INTRODUCTION}

The need to address obesity is now undisputed and pressing. Characterised by excess weight gain [1], obesity is a modern-day health epidemic that requires long-term, individualised care. While the majority of healthcare professionals (HCPs) claim they are confident discussing weight and tailoring management strategies for individuals with overweight and obesity, they also believe that the proportion of patients successfully achieving weight loss goals remains comparatively low [2]. This disconnect between HCPs' assessment of their competency and their effectiveness in counselling individuals to achieve treatment goals represents a central issue in supporting more effective obesity management. It is essential, therefore, that practitioners consider the complex drivers of weight gain across the physiological, environmental and psychosocial spectra. This article provides guidance on how to raise and address weight, and is based on previously conducted studies and does not contain any new studies with human participants or animals performed by any of the authors.

\section{Obesity is a Treatable Disease}

With its numerous compounding factors, obesity is increasingly being recognised as a treatable disease, and health bodies across the globe have begun reclassifying it in acknowledgement [3-5]. Multiple physiological mechanisms interplay to add to the challenge of losing and maintaining weight loss.

Weight loss is associated with marked and persistent alterations in the levels of hormones involved in the regulation of satiety [6]. For example, weight loss in individuals with obesity has been shown to produce sustained reductions in levels of leptin, glucagon-like peptide-1, peptide YY, cholecystokinin, insulin and increased ghrelin $[7,8]$, all of which reduce satiety and may contribute to weight regain. Furthermore, weight loss is associated with changes in neural function and activity, with increased activity in areas associated with processing of food-related stimuli and decreased activity in areas associated with restraining responses to food [9]. Studies also show that people on weight loss diets experience more food cravings than non-dieters, and that these are stronger and more difficult to resist [10]. Finally, diet-induced weight loss is associated with reduction in total and resting energy expenditure [11].

As the biological mechanisms of weight regulation become more clearly understood, it is important that HCPs acknowledge the processes underlying weight regain to enable development of management strategies that not only promote initial weight loss but also maintain that weight change in the long term. 


\section{Patients also advocate obesity being classified as a disease}

Recognising that obesity is a treatable disease is important for HCPs as well as many patients. It not only facilitates a shift in attitude toward managing the disease, but it also enables HCPs and patients to realise there are treatment strategies that are available and effective. Moving away from terms such as 'weight loss' and 'dieting' to terms such as 'obesity treatment planning' can help change the way in which obesity is perceived.

Another key aspect that categorises obesity as a disease is its association with numerous metabolic, mechanical and psychological comorbidities. Excess weight has now been linked to more than 200 diseases [12], and weight loss is associated with clinically meaningful improvements in many of these. Table 1 summarises some of the common complications of obesity. The importance of treating obesity is further illustrated by accumulating evidence of its association with more severe COVID-19 infection, leading to increased risk of hospitalization, admission to intensive care units and death [13].

\section{The 5 As Approach to Obesity Counselling}

There are a number of frameworks aimed at helping HCPs better support people to manage

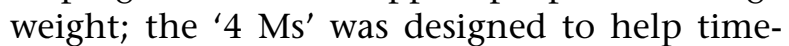

the Canadian Obesity Network to aid the delivery of meaningful weight management consultations, and has proven effective in improving physician-patient communication, patient motivation [26, 27], and HCPs' confidence in discussing weight loss interventions [28]. This paper shares practical solutions to common challenges faced by HCPs, using the flow of the 5 As framework (ask, assess, advise, agree, assist) and incorporating the views and experiences of a person living with obesity.

\section{Ask Permission: Starting the Conversation} Individuals living with obesity experience body weight stigma in multiple aspects of their life, which can lead to feelings of guilt, shame and self-criticism [29]. With this in mind, it is important to be aware of behaviours that could trigger such negative feelings and result in a reluctance to discuss weight.

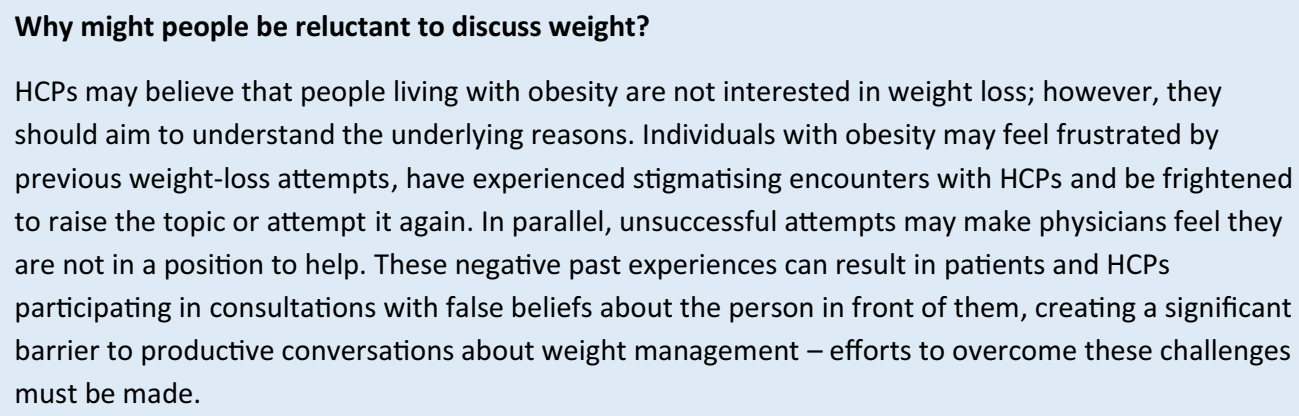

restricted physicians assess for obesity [24], and the newer 'ABCDEF' approach provides guidance on taking a weight history, previous weight loss attempts, evaluation for weight-related morbidities, treatment and long-term follow-up [25]. The 5 As model was developed by
As part of the management approach, HCPs should consider why the individual has visited the clinic; it may not always be appropriate to begin with a conversation about weight. Addressing the presenting complaint first can 
help to reduce feelings of stigmatisation and set up the consultation for success.

While it can be difficult to raise the topic of weight, there are several strategies that can help. Being non-judgmental and empathetic positively opens up the conversation [30], reduces fear of stigma and criticism and helps to form a strong patient-provider partnership. quent management steps. Routinely asking all patients if weight can be checked as part of a consultation eliminates the possibility of underestimation, thus reducing the risk of continued, undetected weight gain [32]. Measuring waist circumference in addition to BMI can also be helpful in evaluating cardiometabolic risk in some individuals [33].

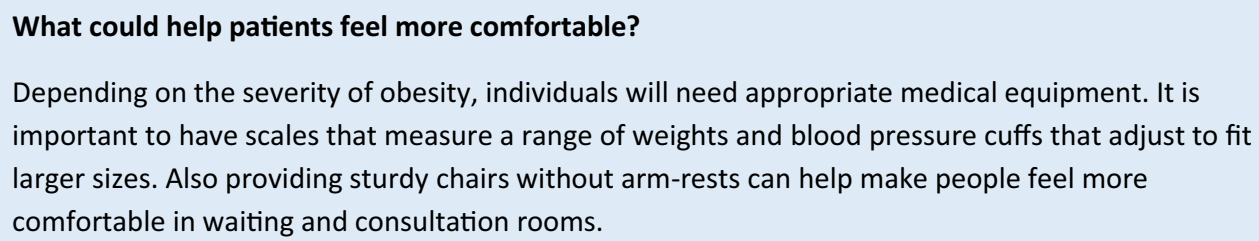

Evidence and experience suggest that a vital step in the intervention process is asking for permission to raise the sensitive issue of weight [28]. A respectful example of such a question might be 'Can we talk about your weight today?' However, language and wording may vary depending on individual HCP preference, language and culture. If the individual wishes to talk about weight, the next step is to acknowledge and advise that weight management is challenging and express willingness to provide ongoing support. However, it is important to note that not all people will feel ready to discuss their weight. Instead of persisting, the optimal course of action may be to ask whether they would be open to revisiting the topic in the future; again, putting the decision into the hands of the individual.

\section{Assessment}

An obvious but frequently omitted step in the assessment process is asking the patient to check their weight. A recent survey found that more than half of primary care physicians (PCPs) were unable to visually assess body mass index (BMI), with the majority underestimating it [31]. Visual assessment is a poor way of determining an individual's weight; as with any other condition, e.g. hypertension, an accurate assessment is essential for informing subse-
A key component in delivering individualised weight loss interventions is the identification of the root causes and drivers of weight gain. Taking a weight history assessing the individual's weight onset, triggering factors, impact of weight on quality of life, previous weight loss attempts, life events during previous weight loss attempts and pattern of weight gain should be explored [25]. The use of open questions by the HCP enables active listening and encourages the individual to share their experience. Determining such factors can enable both the HCP and the person living with obesity to gain a clear picture of what the drivers of weight gain might be, facilitating the development of tailored care plans. Furthermore, this step could disclose whether a new patient has come to the clinic having already lost weight, informing subsequent management steps.

\section{Advise}

A recent survey found that many healthcare professionals see limited clinical value in a $5-10 \%$ weight loss [2]. However, there is good evidence that modest weight losses can reduce the risk and improve the management of obesity-related complications (Fig. 1). 


\begin{abstract}
How should you relay this message?
While it is important for HCPs to understand the specific health complications associated with overweight and obesity, listing these to individuals can be counter-productive. Reiterating the negative aspects of obesity without offering a realistic solution can contribute to feelings of helplessness and make individuals despair of ever being able to make the necessary changes to manage weight and reduce their risk for multiple comorbidities. In addition, emphasising that individuals need to lose weight to prevent these negative health consequences could undermine weight losses the individual has already succeeded in making. A more suitable approach might be to advise people more broadly on the adverse effects of excess weight while iterating that even small weight losses can improve these risks.
\end{abstract}

Advising individuals with overweight/obesity of the health benefits of $5-10 \%$ weight loss can help to centre the consultation on realistic expectations. Delivery is key, as avoiding jargon and using patient-friendly terminology has proven more impactful than using unfamiliar medical terminology [34], e.g. 'increased risk for T2D' versus 'hyperglycaemia'.

During weight loss counselling, HCPs should keep in mind the identified root causes for each individual and explore the modifiable aspects with them to incorporate into a tailored weight management plan. Advice may centre around

\section{Agree}

Having given advice on the relevant aspects of weight, a plan should be agreed, which is a common pitfall in trying to achieve too much too fast. Goals should be specific, measurable, achievable, relevant and timely (SMART) to increase the likelihood of success [36]. An example of a SMART goal is 'I will walk for 20 min at lunchtime on Monday, Wednesday and Friday', which is more constructive than agreeing a vague plan to 'start exercising'.

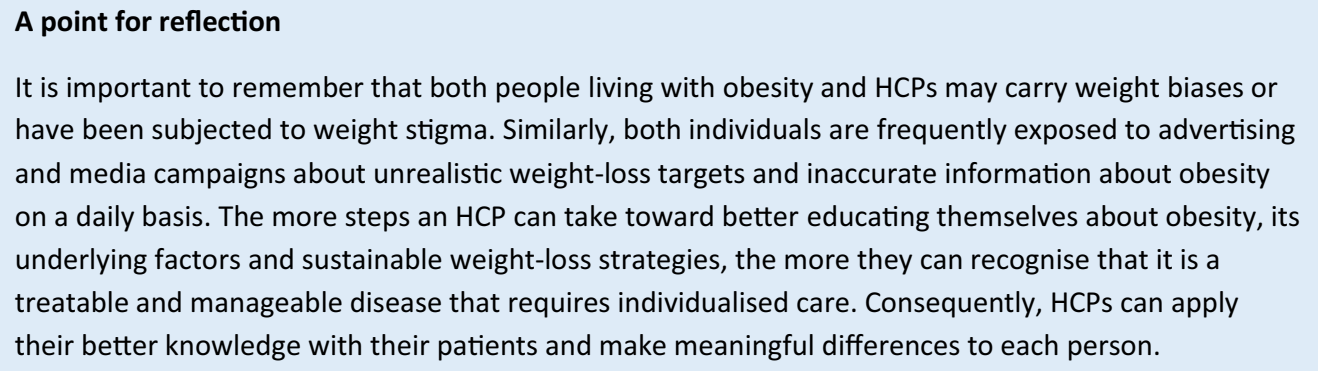

eating well (which foods to incorporate in each meal and how much; caloric density of specific foods and alcoholic beverages), being physically active (to support weight loss and for general health), and addressing psychological aspects related to weight (e.g. binge eating, emotional eating), behavioural therapy, medications and referral to bariatric surgery services in some cases [35].
While it is important to consider the health benefits of a 5-10\% weight reduction when setting targets, losing $5-10 \%$ of baseline body weight as a first attempt might be unrealistic for some individuals. Setting unrealistic weight loss goals is not only common among HCPs, as people often visit practitioners hoping to reduce weight at a rate that is unlikely to be sustainable in the long term [37]. Thus, setting clear HCP and patient expectations from the very beginning is key for avoiding disappointment if goals are not met. In addition, HCPs should work 
collaboratively with individuals to create plans that aim to reduce weight at a comfortable pace for each person [38]. For example, this might involve setting smaller targets as opposed to setting the first target as the total desired weight loss. Unrealistic goals may result in failure [39], which could deter individuals from re-attempting weight loss. A weight loss of $5 \mathrm{~kg}$ may be

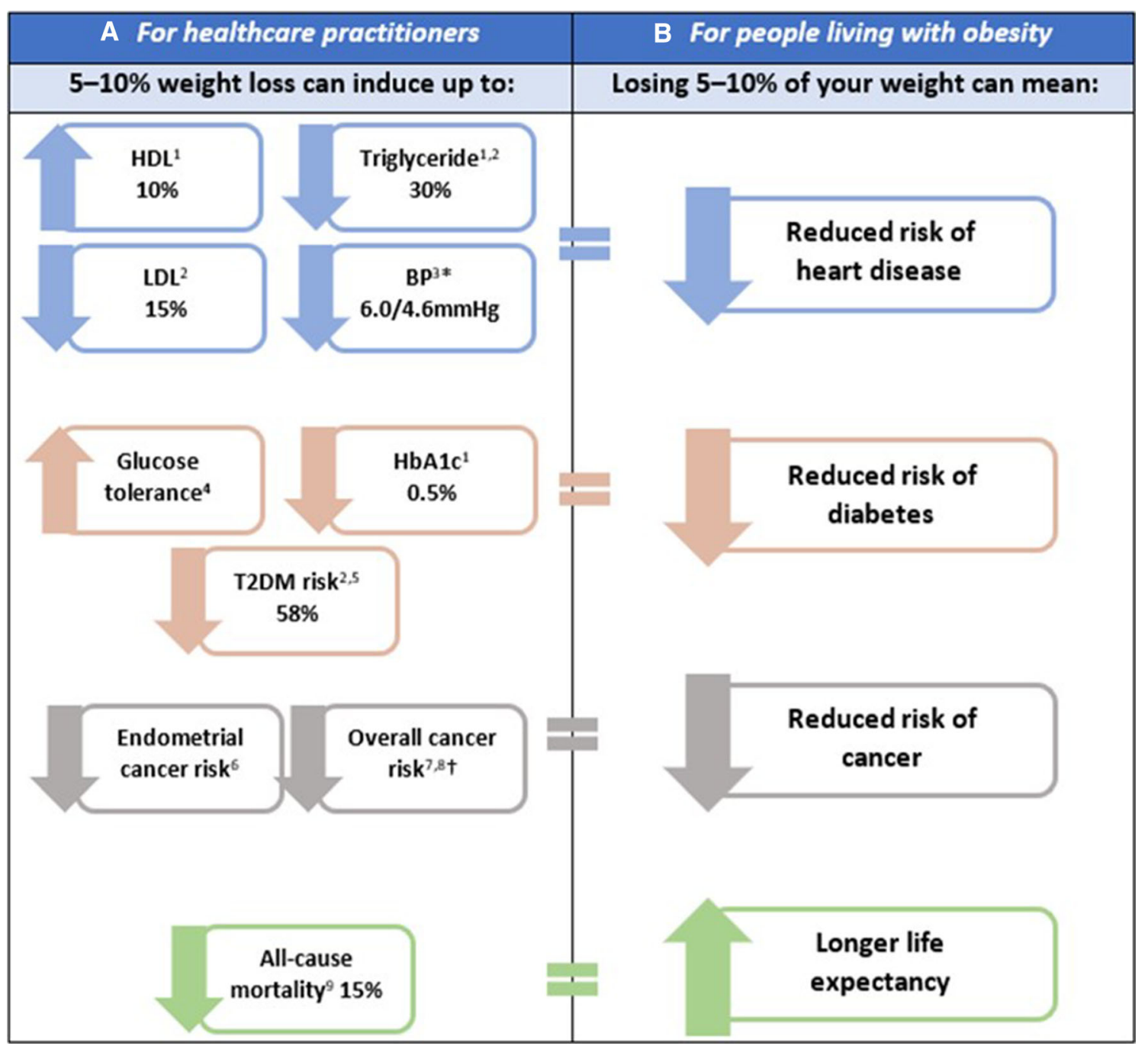

Fig. 1 Health benefits of a 5-10\% weight loss. a Detailed summary of health benefits that can be achieved with a 5-10\% weight loss from baseline including quantitative/measurable benefits on cardiometabolic and glycaemic parameters, and life expectancy. b Simplified version of the health benefits that are achievable with a 5-10\% weight loss, in patient-friendly language. $H D L$ high-density lipoprotein, $L D L$ low-density lipoprotein, BP blood pressure, $H b A 1 C$ haemoglobin Alc, T2DM type 2 diabetes mellitus; ${ }^{*}$ with $10 \mathrm{~kg}$ weight loss; ${ }^{\dagger}$ in individuals who have undergone bariatric surgery. References: 1 Wing RR, et al. Diabetes Care. 2011; 34: 1481-6. 2 Van Gaal L, et al. Eur Heart J 2005; 7: 21-6. 3 Aucott L, et al. Hypertension. 2005; 45: 1035-41. 4 Lindstrom J, et al. Diabetes Care 2003; 26: 3230-6. 5 Tuomilehto et al. N Engl J Med 2001; 344: 1343-50. 6 Luo J, et al. Oncotarget 2017; 8: 81,719-720. 7 Tee MC, et al. Surg Endosc. 2013; 24: 4449-56. 8 National Cancer Institute: Obesity and Cancer Available at: https://www.cancer.gov/about-cancer/causes-prevention/risk/ obesity/obesity-fact-sheet, accessed 25 September 2019. 9 Kritchevsky SB, et al. PLoS ONE 2015; 10: e0121993 
Table 1 Summary of common obesity-related complications

\begin{tabular}{|c|c|c|}
\hline $\begin{array}{l}\text { Increased risk } \\
\text { for }\end{array}$ & \multicolumn{2}{|l|}{ Evidence } \\
\hline T2D $[14-16]$ & $\begin{array}{l}\text { 1.5-fold increased risk with BMI of } 25.0 \\
5 \text { times increased risk with BMI of } \geq 40 \\
\text { Elevated risk in Asian population due to } \\
\text { compared with Caucasian population }\end{array}$ & $\begin{array}{l}.9 \mathrm{~kg} / \mathrm{m}^{2} \\
/ \mathrm{m}^{2} \\
\text { eater prevalence of visceral versus peripheral adiposity }\end{array}$ \\
\hline CVD $[16,17]$ & Greater waist circumference associated with development of disease & $\begin{array}{l}\text { development of disease } \\
\text { by high BMI is increased } 2-3 \text {-fold in people with obesity }\end{array}$ \\
\hline NAFLD [18] & \multicolumn{2}{|c|}{ Positive correlation between BMI and disease severity } \\
\hline $\mathrm{OA}[19]$ & \multicolumn{2}{|l|}{ Weight is greatest modifiable risk factor } \\
\hline OSA $[20]$ & \multicolumn{2}{|c|}{$>10$-fold increased risk with $\mathrm{BMI}>29.0 \mathrm{~kg} / \mathrm{m}^{2}$} \\
\hline GORD [21] & \multicolumn{2}{|c|}{ 1.9-fold increased risk with $\mathrm{BMI}$ of $\geq 30 \mathrm{~kg} / \mathrm{m}^{2}$} \\
\hline Cancer $[22]$ & \multicolumn{2}{|c|}{$\begin{array}{l}\text { Strong evidence for increased cancer risk related to excess body weight across colorectal, oesophageal, } \\
\text { kidney and pancreatic cancers across both sexes } \\
\text { Strong evidence for increased risk of endometrial cancer and post-menopausal breast cancer in women }\end{array}$} \\
\hline Depression [23] & \multicolumn{2}{|c|}{ People with obesity have $55 \%$ increased risk of developing depression } \\
\hline \multicolumn{3}{|c|}{$\begin{array}{l}C V D \text { cardiovascular disease, GORD gastroesophageal reflux disorder, } N A F L D \text { non-alcoholic fatty liver disease, } O A \\
\text { osteoarthritis, } O S A \text { obstructive sleep apnoea, T2D type } 2 \text { diabetes. }\end{array}$} \\
\hline $\begin{array}{l}\text { clinically me } \\
\text { reduction for } \\
\text { individuals m } \\
\text { an important } \\
\text { before. Small } \\
\text { should be rec } \\
\text { must be shif } \\
\text { vidual's capal } \\
\text { Having est } \\
\text { realistic, pers } \\
\text { agree the spe } \\
\text { Eating behavi } \\
\text { loss interven } \\
\text { ges, individu }\end{array}$ & $\begin{array}{l}\text { aningful in terms of risk factor } \\
\text { some individuals, and in other } \\
\text { ay improve the ability to carry out } \\
\text { daily task that was not possible } \\
\text { accomplishments such as these } \\
\text { ggnised as successes, and attitudes } \\
\text { ed in alignment with each indi- } \\
\text { ilities. } \\
\text { ablished the importance of setting } \\
\text { onalised goals, the next step is to } \\
\text { cific elements of a helpful plan. } \\
\text { ours are a key target of all weight- } \\
\text { ions and, in order to elicit chan- } \\
\text { ls must assess their typical eating }\end{array}$ & $\begin{array}{l}\text { patterns and identify aspects they wish to } \\
\text { change [40]. Individuals may have endured } \\
\text { stigmatising conversations about their dietary } \\
\text { habits in the past, therefore it is important to } \\
\text { ask permission to discuss it. An appropriate } \\
\text { question might be, 'Would it be helpful to look } \\
\text { in a bit more detail at how food or activity is } \\
\text { fitting into your typical day?' Following identi- } \\
\text { fication of dietary habits, through use of, e.g., a } \\
\text { food diary, the HCP and patient can explore } \\
\text { together any the specific dietary changes that } \\
\text { might be helpful, such as increasing fibre and } \\
\text { protein intake, and reducing intake of energy- } \\
\text { dense foods and drinks [5]. }\end{array}$ \\
\hline
\end{tabular}


Alongside tracking eating behaviours, HCPs may also encourage individuals to self-monitor physical activity patterns and weight. Care providers should encourage individuals to set goals relative to their current mobility and to slowly increase the amount of time the person is active [38]. In parallel with reducing the burden of obesity-related complications, physical activity and associated weight loss should aim to improve an individual's quality of life. weight loss of greater than $10 \%$ is unlikely with behavioural changes alone, due to metabolic adaptations. Consequently, while behavioural interventions are the basis of all weight management interventions, pharmacotherapy and/ or bariatric surgery should be considered for additional benefits [40].

Eligibility for pharmacotherapy or bariatric surgery is based on degree of obesity (usually determined by BMI and/or waist circumference)

Small changes really do make a difference
Advising individuals with obesity to make small increases in their movement can go a long way in
improving mobility and enabling people to perform tasks that are important to them. For example, if a
person is able to walk for 5 minutes at a time, advising them to increase their mobile time by 30
seconds each day could eventually mean they are able to walk to the bus stop or to work. Other
achievements might include being able to try their own shoelaces, fit into a cinema seat or fasten a car
seat belt. Being able to do these things again can make a real difference in the quality of a patient's
life. Successfully achieving these small goals on a regular basis can build an individuals' confidence in
their ability to make positive changes. Consequently, people are more likely to lose a sustainable
weight, gradually, over the long term and reach a weight that enables them to lead a fuller life.

Although possible according to trials such as the DiRECT trial of an intensive primary careled weight management intervention using total diet replacement for those with T2D [41], and obesity-related comorbidities. Eligibility criteria are similar across regions [5, 40, 42-44], although BMI cutoff values are lower in Asian populations [45] (Fig. 2). Rather than offering

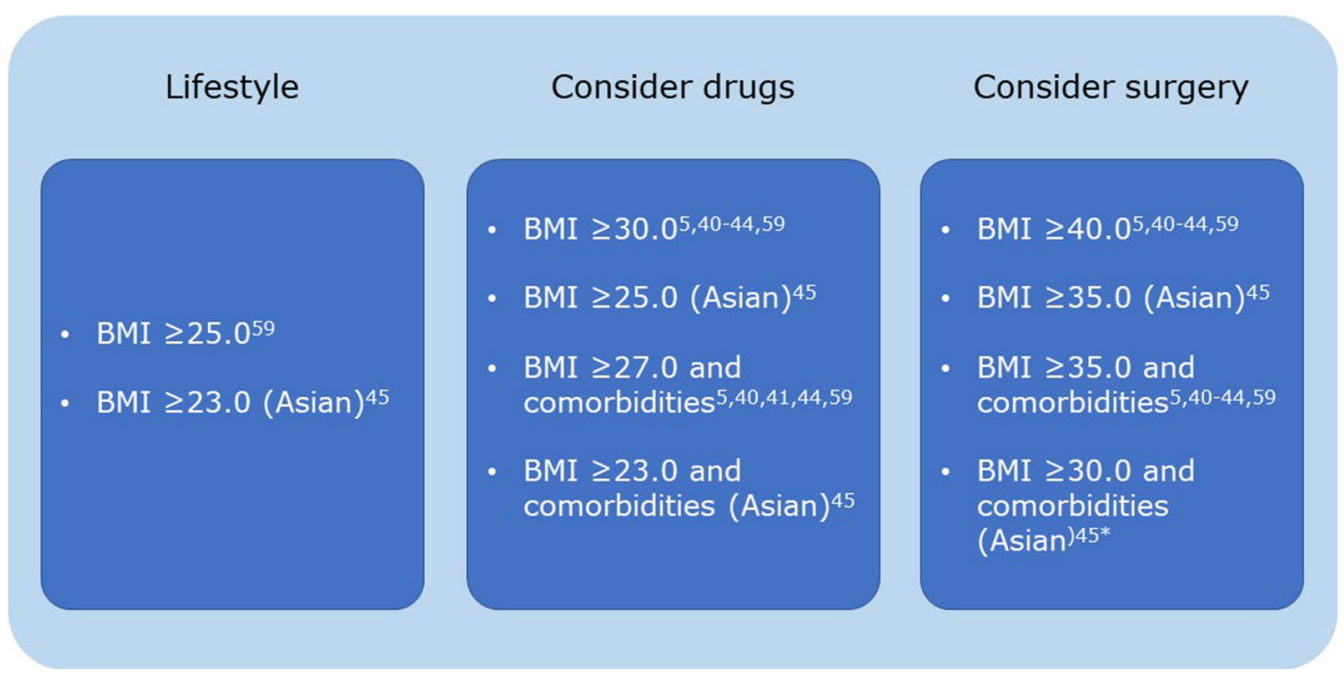

Fig. 2 Guidance on level of intervention to consider [5, 40-45, 59]. BMI body mass index (reported in $\mathrm{kg} / \mathrm{m}^{2}$ ). Consult local guidelines for specific recommendations. *In some non-Asian regions, people with type 2 diabetes can be considered 
Table 2 Summary of dosing regimens of available and investigational weight management pharmacotherapies

\begin{tabular}{|c|c|c|}
\hline & Route of administration & Dose \\
\hline Orlistat $[46-48]$ & Oral & $\begin{array}{l}\text { Prescription: } 120 \mathrm{mg} \text { three times daily } \\
\text { OTC: } 60 \mathrm{mg} \text { three times daily }\end{array}$ \\
\hline Phentermine/topiramate $[49,50]$ & Oral & Up to $15 \mathrm{mg} / 92 \mathrm{mg}$ daily \\
\hline Liraglutide $[51,52]$ & Subcutaneous & $3 \mathrm{mg}$ daily \\
\hline Naltrexone/bupropion $[53,54]$ & Oral & Up to $32 \mathrm{mg} / 360 \mathrm{mg}$ daily \\
\hline Semaglutide $^{a}[55]$ & Subcutaneous & $2.4 \mathrm{mg}$ daily \\
\hline
\end{tabular}

Weight management agents should always be used in conjunction with appropriate behavioural interventions

a Semaglutide is an investigational product and has not been approved by the FDA or EMA at the time of writing

behavioural, pharmacotherapy and bariatric surgery sequentially, all relevant options should be discussed with individuals as early as possible (Table 2).

The treatment approach should be agreed between the individual and HCP following consideration of risks, benefits and individual circumstances. When initiating pharmacotherapy, the HCP should stress the importance of ongoing behavioural changes, as all weightmanagement pharmacotherapies are indicated in conjunction with a reduced calorie diet and/ or increased physical activity [47, 49, 51, 53].

\section{Assist}

Regular follow-up is imperative for identifying less successful approaches early, yet, remark- regular weight-related consultations to ensure ongoing support.

Given the complex and multifactorial nature of obesity, it is unsurprising that HCPs may need to refer onward to more specific services. Depending on healthcare systems and available resources, HCPs may need to signpost or refer individuals to more specialist providers such as psychologists, dietitians, physiotherapists, endocrinologists, commercial weight loss programmes, or bariatric centres to ensure all elements of weight gain are managed adequately and appropriately where needed [57]. Indeed, a recent study conducted in the UK found that providing support through referral to specialist services was more effective than solely advising individuals to lose weight [58].

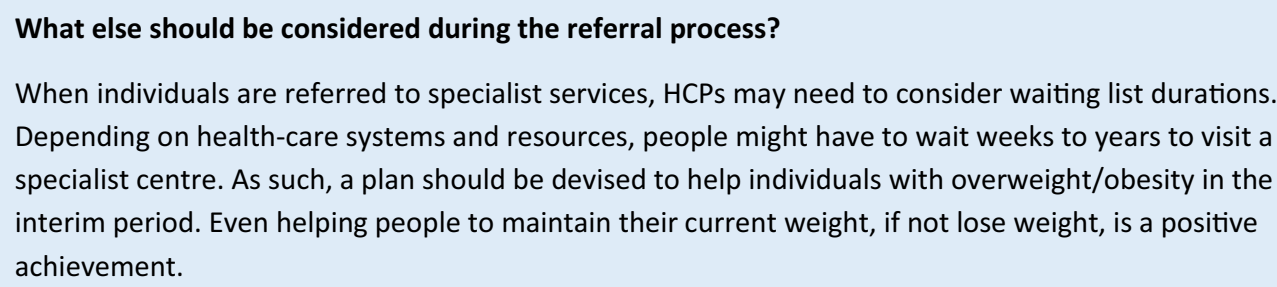

ably, only $24 \%$ of people with obesity in the US report having follow-up appointments in place after their initial weight-loss consultation [56]. HCPs should agree a suitable timeframe for

\section{CONCLUSION}

Obesity rates are rising across the world, and HCPs can play an important role in supporting individuals to manage this disease. Management should focus on improving health, 
including assessing for and addressing the drivers and complications of obesity. Although PCPs lie at the centre of this approach, efforts to manage overweight and obesity should be shared among all care providers to ensure the delivery of interventions that consider the environmental and psychosocial influences that impact obesity at a behavioural level, while addressing the physiological and psychological challenges of long-term weight management. the work as a whole, and have given their approval for this version to be published.

Author contributions. Professor Donal O'Shea, Dr. Cathy Breen, Dr. Scott Kahan, Miss Lorna Lennon were involved in all aspects of manuscript development.

Disclosures. Professor Donal O'Shea has received honoraria/consultation fees from Novo Nordisk, GlaxoSmithKline and Menarini. Dr.

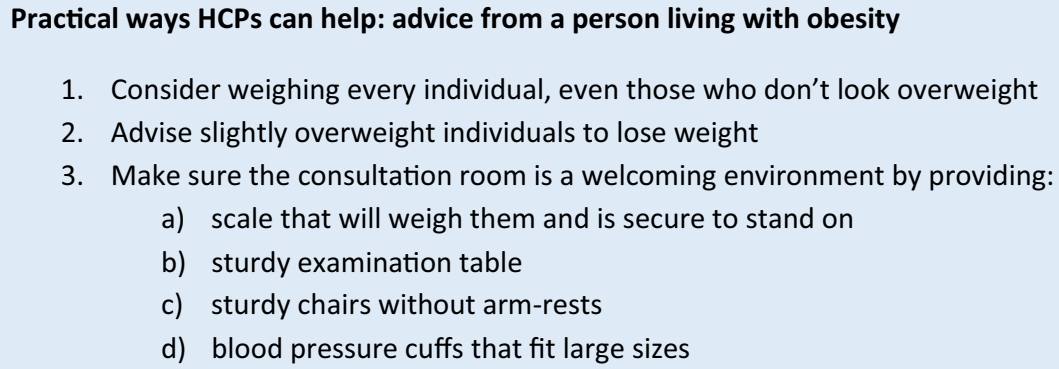

4. Understand that every person is an individual and should be treated as such

5. Offer practical advice by keeping an information sheet that lists:

a) where your patient can buy suitable weighing scales in the local area

b) where they can buy a step counter

c) local weight loss meetings, including commercial support groups where available

6. Treat what the person came in for before mentioning their weight

7. Emphasise the benefits of small weight losses

8. Emphasise the benefits of small increases in movement

9. Enter a consultation with realistic expectations

10. Ensure the patient goes away with realistic expectations about weight losses

11. Be a part of the solution, not a part of the problems your patient has probably faced until now

\section{ACKNOWLEDGEMENTS}

Funding. The journal's Rapid Service fee for this manuscript has been supported by an educational grant from Novo Nordisk A/S.

Editorial Assistance. The authors are grateful to Ruth Wills and Fay Pickering of International Medical Press for editorial support in the development of this manuscript.

Authorship. All named authors meet the International Committee of Medical Journal Editors (ICMJE) criteria for authorship for this article, take responsibility for the integrity of
Cathy Breen has received honoraria and had conference attendance sponsored by MSD, AstraZeneca, Sanofi-Aventis, Roche and Eli-Lily. Ms Lorna Lennon and Dr. Scott Kahan have nothing to disclose.

Compliance with Ethics Guidelines. This article is based on previously conducted studies and does not contain any new studies with human participants or animals performed by any of the authors.

Open Access. This article is licensed under a Creative Commons Attribution-NonCommercial 4.0 International License, which permits 
any non-commercial use, sharing, adaptation, distribution and reproduction in any medium or format, as long as you give appropriate credit to the original author(s) and the source, provide a link to the Creative Commons licence, and indicate if changes were made. The images or other third party material in this article are included in the article's Creative Commons licence, unless indicated otherwise in a credit line to the material. If material is not included in the article's Creative Commons licence and your intended use is not permitted by statutory regulation or exceeds the permitted use, you will need to obtain permission directly from the copyright holder. To view a copy of this licence, visit http://creativecommons.org/licenses/by$\mathrm{nc} / 4.0 /$.

\section{REFERENCES}

1. Seaman DR. Weight gain as a consequence of living a modern lifestyle: a discussion of barriers to effective weight control and how to overcome them. J Chiropr Humanit. 2013;20:27-35.

2. Leiter LA, Astrup A, Andrews RC, et al. Identification of educational needs in the management of overweight and obesity: results of an international survey of attitudes and practice. Clin Obes. 2015;5: 245-55.

3. Kyle TK, Dhurandhar EJ, Allison DB. Regarding obesity as a disease: evolving policies and their implications. Endocrinol Metab Clin N Am. 2016;45:511-20.

4. Aronne LJ, Nelinson DS, Lillo JL. Obesity as a disease state: a new paradigm for diagnosis and treatment. Clin Cornerstone. 2009;9:26-9.

5. Yumuk V, Tsigos C, Fried M, et al. European guidelines for obesity management in adults. Obes Facts. 2015;8:402-24.

6. Sumithran P, Prendergast LA, Delbridge E, et al. Long-term persistence of hormonal adaptations to weight loss. N Engl J Med. 2011;365:1597-604.

7. Varady KA, Tussing L, Bhutani S, Braunschweig CL. Degree of weight loss required to improve adipokine concentrations and decrease fat cell size in severely obese women. Metab Clin Exp. 2009;58: 1096-101.
8. Adam TC, Jocken J, Westerterp-Plantenga MS. Decreased glucagon-like peptide 1 release after weight loss in overweight/obese subjects. Obes Res. 2005;13:710-6.

9. Hinkle W, Cordell M, Leibel R, Rosenbaum M, Hirsch J. Effects of reduced weight maintenance and leptin repletion on functional connectivity of the hypothalamus in obese humans. PLoS ONE. 2013;8:e59114.

10. Massey A, Hill AJ. Dieting and food craving. A descriptive, quasi-prospective study. Appetite. 2012;58:781-5.

11. Muller MJ, Enderle J, Bosy-Westphal A. Changes in energy expenditure with weight gain and weight loss in humans. Curr Obes Rep. 2016;5:413-23.

12. Kahan SI. Practical strategies for engaging individuals with obesity in primary care. Mayo Clin Proc. 2018;93:351-9.

13. Popkin BM, Du S, Green WD, et al. Individuals with obesity and COVID-19: a global perspective on the epidemiology and biological relationships. Obes Rev. 2020;21:e13128.

14. Hsu WC, Araneta MR, Kanaya AM, Chiang JL, Fujimoto W. BMI cut points to identify at-risk Asian Americans for type 2 diabetes screening. Diabetes Care. 2015;38:150-8.

15. Ganz ML, Wintfeld N, Li Q, et al. The association of body mass index with the risk of type 2 diabetes: a case-control study nested in an electronic health records system in the United States. Diabetes Metab Syndr. 2014;6:50.

16. Balkau B, Deanfield JE, Despres JP, et al. International Day for the Evaluation of Abdominal Obesity (IDEA): a study of waist circumference, cardiovascular disease, and diabetes mellitus in 168,000 primary care patients in 63 countries. Circulation. 2007;116:1942-51.

17. Calle EE, Thun MJ, Petrelli JM, Rodriguez C, Heath CW Jr. Body-mass index and mortality in a prospective cohort of U.S. adults. N Engl J Med. 1999;341:1097-105.

18. Shen HC, Zhao ZH, Hu YC, Chen YF, Tung TH. Relationship between obesity, metabolic syndrome, and nonalcoholic fatty liver disease in the elderly agricultural and fishing population of Taiwan. Clin Interv Aging. 2014;9:501-8.

19. King LK, March L, Anandacoomarasamy A. Obesity \& osteoarthritis. Indian J Med Res. 2013;138: 185-93. 
20. Pillar G, Shehadeh N. Abdominal fat and sleep apnea. The chicken of the egg? Diabetes Care. 2008;31:S303-9.

21. Hampel H, Abrhaham NS, El-Serag HB. Meta-analysis: obesity and the risk for gastroesophageal reflux disease and its complications. Ann Intern Med. 2005;143:199-211.

22. Basen-Engguist $\mathrm{K}$, Chang M. Obesity and cancer risk: recent review and evidence. Curr Oncol rep. 2013;13:71-6.

23. Luppino FS, de Wit LM, Bouvy PF, Stijnen T, Cuijpers P, Penninx BWJH, et al. Overweight, obesity, and depression: a systematic review and metaanalysis of longitudinal studies. Arch Gen Psychiatry. 2010;67(3):220-9.

24. Sharma AM. M, M, M \& M: a mnemonic for assessing obesity. Obes Rev. 2010;11:808-9.

25. Kahan S, Manson JE. Obesity treatment, beyond the guidelines: practical suggestions for clinical practice. JAMA. 2019;321:1349-50.

26. Welzel FD, Stein J, Pabst A, et al. Five A's counseling in weight management of obese patients in primary care: a cluster-randomized controlled trial (INTERACT). BMC Fam Pract. 2018;19:97-107.

27. Asselin J, Salami E, Osunlana AM, et al. Impact of the 5 As Team study on clinical practice in primary care obesity management: a qualitative study. CMAJ Open. 2017;5:E322-9.

28. Duarte C, Matos M, Stubbs RJ, et al. The impact of shame, self-criticism and social rank on eating behaviours in overweight and obese women participating in a weight management programme. PLoS ONE. 2017;12:e0167571.

29. Thibodeau PH, Uri R, Thompson B, Flusberg SJ. Narratives for obesity: effects of weight loss and attribution on empathy and policy support. Healt Educ Behav. 2017;44:638-47.

30. Hite A, Victorson D, Elue R, Plunkett BA. An exploration of barriers facing physicians in diagnosing and treating obesity. Am J Health Promot. 2019;33:217-24.

31. Kushner RF, Ryan DH. Assessment and lifestyle management of patients with obesity: clinical recommendations from systematic reviews. JAMA. 2014;312:943-52.

32. Fitzpatrick SL, Wischenka D, Appelhans BM, et al. An evidence-based guide for obesity treatment in primary care. Am J Med. 2016;129:115.e1-e7.
33. Sturgiss E, Haesler E, Elmitt N, van Weel C, Douglas $\mathrm{K}$. Increasing general practitioners' confidence and self-efficacy in managing obesity: a mixed methods study. BMJ Open. 2017;7:e014314.

34. Auspitz M, Cleghorn MC, Azin A, et al. Knowledge and perception of bariatric surgery among primary care physicians: a survey of family doctors in Ontario. Obes Surg. 2016;26:2022-8.

35. Gardner J, Kjolhaug J, Linde JA, Sevcik S, Lytle LA. Teaching goal-setting for weight-gain prevention in a college population: insights from the CHOICES study. J Health Educ Teach. 2013;4:39-49.

36. Foster GD, Wadden TA, Vogt RA, Brewer G. What is a reasonable weight loss? Patients' expectations and evaluations of obesity treatment outcomes. J Consult Clin Psychol. 1997;65:79-85.

37. Avery A, Langley-Evans SC, Harrington M, Swift JA. Setting targets leads to greater long-term weight losses and "unrealistic" targets increase the effect in a large community-based commercial weight management group. J Hum Nutr Diet. 2016;29:687-96.

38. Wamsteker EW, Geenen R, Zelissen PM, van Furth $\mathrm{EF}$, Iestra J. Unrealistic weight-loss goals among obese patients are associated with age and causal attributions. J Am Diet Assoc. 2009;109:1903-8.

39. Burke LE, Wang J, Sevick MA. Self-monitoring in weight loss: a systematic review of the literature. J Am Diet Assoc. 2011;111:92-102.

40. Durrer Schutz D, Busetto L, Dicker D, et al. European practical and patient-centred guidelines for adult obesity management in primary care. Obes Facts. 2019;12:40-66.

41. Lean MJ, Leslie WS, Barnes AC, et al. Primary careled weight management for remission of type 2 diabetes (DiRECT): an open-label, cluster-randomised trial. Lancet. 2018;391:541-51.

42. Apovian CM, Garvey WT, Ryan DH. Challenging obesity: patient, provider, and expert perspectives on the roles of available and emerging nonsurgical therapies. Obesity. 2015;23(Suppl 2):S1-26.

43. Australian Government: National Health and Medical Research Council; Department of Health. Clinical Practice Guidelines for the Management of Overweight and Obesity in Adults, Adolescents and Children in Australia. 2013. https://www.nhmrc. gov.au/file/4916/download?token=64LITE0u. Accessed 15 Jan 2021.

44. National Institute for Health and Care Excellence. Obesity: identification, assessment and management. Clinical guideline [CG189]. 2014. https:// 
www.nice.org.uk/guidance/cg189. Accessed 15 Jan 2021.

45. Kim MK, Lee WY, Kang JH, et al. 2014 clinical practice guidelines for overweight and obesity in Korea. Endocrinol Metab. 2014;29:405-9.

46. Hauptman J, Lucas C, Boldrin MN, Collins H, Segal KR. Orlistat in the long-term treatment of obesity in primary care settings. Arch Fam Med. 2000;9:160-7.

47. Ioannides-Demos LL, Piccenna L, McNeil JJ. Pharmacotherapies for obesity: past, current, and future therapies. J Obes. 2011;2011:179674.

48. Xenical (orlistat) Capsules for Oral Use. FDA Prescribing Information. 1999. https://www. accessdata.fda.gov/drugsatfda_docs/label/2012/ 020766s029lbl.pdf. Accessed 15 Jan 2021.

49. Qsymia (phentermine and topiramate extended release) Capsules for Oral Use. FDA Prescribing Information 2012. http://www.qsymiarems.com/ full-prescribing-information.pdf. Accessed 15 Jan 2021.

50. Gadde KM, Allison DB, Ryan DH, et al. Effects of low-dose, controlled-release, phentermine plus topiramate combination on weight and associated comorbidities in overweight and obese adults (CONQUER): a randomised, placebo-controlled, phase 3 trial. Lancet. 2011;377:1341-52.

51. Saxenda (liraglutide) Injection for Subcutaneous Use. FDA Prescribing information 2018. https:// www.accessdata.fda.gov/drugsatfda_docs/label/ 2018/206321s007lbl.pdf. Accessed 25 Sept 2019.

52. Pi-Sunyer X, Astrup A, Fujioka $\mathrm{K}$, et al. A randomized, controlled trial of $3.0 \mathrm{mg}$ of liraglutide in weight management. N Engl J Med. 2015;373: $11-22$.

53. Contrave (naltrexone $\mathrm{HCI}$ and bupropion $\mathrm{HCI}$ ) Extended-Release Tablets. FDA Prescribing information 2014. https://www.accessdata.fda.gov/ drugsatfda_docs/label/2014/200063s000lbl.pdf. Accessed 15 Jan 2021.

54. Wadden TA, Foreyt JP, Foster GD, et al. Weight loss with naltrexone SR/bupropion SR combination therapy as an adjunct to behavior modification: the COR-BMOD trial. Obesity. 2011;19:110-20.

55. Wilding J, Batterham R, Calanna S, et al. Onceweekly semaglutide in adults with overweight or obesity. N Engl J Med. 2021;384:989.

56. Kaplan LM, Golden A, Jinnett K, et al. Perceptions of barriers to effective obesity care: results from the National ACTION Study. Obesity. 2018;26:61-9.

57. Montesi L, El Ghoch M, Brodosi L, et al. Long-term weight loss maintenance for obesity: a multidisciplinary approach. Diabetes Metab Syndr Obes. 2016;9:37-46.

58. Aveyard P, Lewis A, Tearne S, et al. Screening and brief intervention for obesity in primary care: a parallel, two-arm, randomised trial. Lancet. 2016;388:2492-500.

59. Apovian CM, Aronne LJ, Bessesen DH, et al. Pharmacological management of obesity: an endocrine Society clinical practice guideline. J Clin Endocrinol Metab. 2015;100:342-62.

60. Rueda-Clausen CF, Benterud E, Bond T, et al. Effect of implementing the 5 As of obesity management framework on provider-patient interactions in primary care. Clin Obes. 2014;4:39-44. 